\title{
SENYAWA GOLONGAN STEROID DARI EKSTRAK $n$-HEKSANA KULIT BATANG KAYU BITTI (Vitex cofassus) DAN UJI TOKSISITAS TERHADAP Artemia salina Leach.
}

\author{
Asriani Ilyas*, Iin Novianty \& Irmayanti \\ Jurusan Kimia, Fakultas Sains dan Teknologi, UIN Alauddin Makassar \\ *Alamat korespondensi: ayyi_ilyas@yahoo.co.id
}

\begin{abstract}
Abstrak : Penelitian telah dilakukan untuk mengidentifikasi dan mengkarakterisasi senyawa bioaktif dari kulit batang kayu bitti (Vitex cofassus), suatu tumbuhan endemik dari Sulawesi yang termasuk famili Verbenaceae. Tahapan penelitian meliputi maserasi, fraksinasi, pemurnian, identifikasi dan uji toksisitas. Ekstraksi dilakukan dengan metode maserasi menggunakan $n$-hexane. Tahapan identifikasi meliputi melibatkan uji warna,analisis KLT, analisis IR, sedangkan uji toksisitas menggunakan metode BSLT dengan Artemia salina Leach sebagai bioindikator. Hasil penelitian adalah senyawa dengan bentuk kristal jarum berwarna putih dengan 0,4745 gram dan analisis fitokimia menunjukkan bahwa senyawa tersebut adalah senyawa golongan steroid. Hal ini juga didukung oleh data IR yang menunjukkan gugus fungsi kelompok steroid. Uji toksisitas menunjukkan harga $\mathrm{LC}_{50}$ pada ekstrak, fraksi, dan senyawa murni berturut-turut sebesar 74,079 ug/ml, 118,850 ug/ml and 88,201 ug/ml. Data ini menunjukkan bahwa seyawa murni yang dihasilkan adalah murni.
\end{abstract}

Kata kunci: Artemia salina, BSLT method, Vitex cofassus, Steroid, Toksisitas.

\begin{abstract}
Research had been conducted to identify and characterize bioactive compound of the bark of Vitex cofassus, an endemic plant from Sulawesi that belongs to family of Verbenaceae. The phase of research include extraction, fractionation, purification, identification and toxicity test. Extraction was carried out by maceration method using n-hexane. Identification steps include color test, TLC and IR spectroscopy analysis, whereas toxicity test using BSLT method with Artemia Salina Leach as bioindicator. The results of the research obtained a compound in the form of a white crystalline needle-shaped that showed the weight of 0.4745 grams and the phytochemical analysis showed that the compound is steroid group. This was supported by the IR spectrum, which revealed steroid functional group. Toxicity test showed the $L C_{50}$ value on extract of $n$-hexane, fractions and pure compounds were respectively $74.079 \mathrm{ug} / \mathrm{ml}, 118.850 \mathrm{ug} / \mathrm{ml}$ and $88.201 \mathrm{ug} / \mathrm{ml}$. This indicates that the compounds are toxic.
\end{abstract}

Keyword: Artemia salina, BSLT method, Vitex cofassus, Steroid, Toxicity.

\section{PENDAHULUAN}

Kanker menjadi masalah utama kesehatan baik di negara maju maupun negara berkembang. Saat ini pengobatan penyakit kanker, sebagian besar menimbulkan resistensi, menyebabkan efek samping dan biayanya relatif mahal. Upaya eksplorasi bahan alam sebagai obat kanker merupakan salah satu hal yang dapat dilakukan dalam mengembangkan pengobatan alternatif yang lebih murah. Tumbuhan merupakan salah satu sumber daya alam yangpentingkarena merupakan tempat terjadinya sintesis senyawa organik yang kompleks sehingga menghasilkan sederet golongan senyawa dengan berbagai macam struktur. Indonesia merupakan negara dengan tingkat keanekaragaman hayati yang sangat tinggi dan dikenal sebagai Negara megabiodiversity. Keanekaragaman ini disebabkan oleh letak Indonesia yang strategis di antara dua benua yaitu benua Asia dan benua Australia, serta dua samudra yaitu samudra Hindia dan samudra Pasifik, sehingga berbagai jenis tumbuhan yang ada di
Indonesia merupakan perpaduan antara dua benua tersebut. Menurut survei yang dilakukan PT Eisai, di Indonesia terdapat sekitar 7000spesies tumbuhan obat, yang berarti sekitar $90 \%$ dari seluruh jenis tumbuhan obatyang ditemukan di Asia, dari jumlah tersebut baru sedikit sekali yang benar-benar dimanfaatkan dalam pengobatan. Menurut catatan sebanyak 14 spesies dari 45 spesies tumbuhan yang diimpor oleh Amerika Serikat sebagai bahan bakuobat penting berasal dari Indonesia. Sulawesi merupakan salah satu daerah di Indonesia yang memiliki kekayaan alam yang cukup unik dan menarik perhatian banyak ilmuwan dan penjelajah alam.Keunikan ini tak terlepas dari akibat pengaruh 2 daratan benua yang dalam sejarahnya telah ikut membentuk pulau yang dikenal sebagai areal peralihan flora fauna Laurasia dan Gondwanaland. Sekitar 5000 jenis tumbuhan diduga merupakan jenis-jenis endemik Sulawesi dan beberapa jenis diantaranya berpotensi ekonomi dalam berbagai industri kayu, obat, maupun sumber pangan (Hidayat \& Munawaroh, 2009). 
Kayu Bitti (Vitex cofassus ) merupakan salah satu jenis tumbuhan endemik di Sulawesi atau di beberapa daerah dikenal pula dengan nama gofasa. V. cofassus telah dimanfaatkan oleh masyarakat Sulawesi Selatan sebagai bahan kayu bangunan dan merupakan jenis kayu unggulan Sulawesi Selatan (Gusmiaty dkk., 2012), namun eksplorasi $V$. cofassus untuk dikembangkan sebagai tumbuhan obat masih sangat jarang. Sejauh ini, belum diketahui senyawa aktif dalam $V$. cofassus yang berpotensi sebagai antikanker. Akan tetapi, dari beberapa penelitian membuktikan bahwa tumbuhan yang berada satu genus dengan $V$. cofassus telah mempunyai efek farmakologi sebagai antikanker. Salah satu diantaranya adalah tumbuhan legundi ( $V$. trifolia). Secara kemotaksonomi, aktivitas kimiawi satu spesies dengan spesies lain dalam satu genus atau famili pada prinsipnya adalah sama secara kualitatif dan akan berbeda secara kuantitatif.

Selain itu, afinitas kimiawi dalam satu genus memiliki hubungan kekerabatan molekul. Berdasarkan data-data ilmiah dari penelitian pada tumbuhan legundi ( $V$. trifolia), maka peneliti berinisiatif mengisolasi senyawa bioaktif dari kulit batang kayu bitti ( $V$. cofassus) yang berpotensi sebagai anti kanker. Pada uji toksisitas ekstrak kulit batang kayu bitti ( $V$. cofassus) diterapkan metode pengujian BSLT dengan menggunakan Artemia salina karena dianggap memiliki korelasi dengan daya sitotoksik senyawa-senyawa antikanker, sehingga sering dilakukan untuk skrining awal pencarian senyawa antikanker.

Adapun tujuan dari penelitian ini adalah: (1) untuk mengidentifikasi dan mengkarakterisasi senyawa bioaktif antikanker yang terdapat dalam ekstrak $n$-heksana kulit batang kayu bitti (V. cofassus) dan (2) untuk menentukan nilai bioaktivitas senyawa antikanker dari kulit batang kayu bitti ( $V$. cofassus) terhadap kematian larva Artemia salina Leach.

\section{BAHAN DAN METODE PENELITIAN Alat}

Penelitian ini menggunakan alat-alat gelas, rotary evaporator, chamber, corong sintered glass, lampu UV 254-366 nm, lampu pijar, kolom kromatografi gravitasi, neraca analitik, oven, alat penyemprot, pompa vakum, pipa kapiler, kaca pembesar, mikropipet, botol vial, cutter dan alat spektrofotometer FTIR Prestige 21 merek Shimadzu.

\section{Bahan}

Bahan yang digunakan dalam penelitian ini antara lain Bahan yang digunakan adalah kulit batang kayu bitti (Vitex cofassus), akuades, akuabides, pelarut etanol, metanol, $n$-heksana, etil asetat, kloroform, aseton, dimetil sulfoksida (DMSO) pereaksi Mayer, pereaksi Liebermann-Buchard, besi (III) klorida
$\left(\mathrm{FeCl}_{3}\right) 5 \%$, pereaksi Wagner, pereaksi Dragendroff, asam sulfat $\left(\mathrm{H}_{2} \mathrm{SO}_{4}\right) 10 \%$, asam sulfat $\left(\mathrm{H}_{2} \mathrm{SO}_{4}\right)$ pekat, natrium hidroksida $(\mathrm{NaOH}) 10 \%$, natrium klorida $(\mathrm{NaCl})$ murni, silika $\mathrm{G}_{60}(230-400$ mesh) Merck nomor katalog 7730, 7733 dan 7734 , silika gel $\mathrm{G}_{60}$ PF 254, aluminium foil, kertas saring dan telur Artemia salina Leach.

\section{Prosedur Kerja \\ Ekstraksi}

Kulit batang kayu bitti dibersihkan kemudian ditumbuk kasar dan dikeringkan dengan cara di anginanginkan selama kurang lebih satu bulan sampai diperoleh berat konstan selanjutnya hasilnya digunakan sebagai sampel penelitian. Ekstraksi komponen aktif dilakukan dengan cara ekstraksi maserasi atau perendaman. Serbuk kulit batang kayu bitti ditimbang sebanyak $1,5 \mathrm{~kg}$ dan diekstraksi secara maserasi menggunakan pelarut $n$-heksana selama 24 jam sebanyak 3x. Kemudian filtrat yang dihasilkan ditampung dan dipekatkan dengan menggunakan rotary evaporator. Selanjutnya hasil pemekatan digunakan untuk uji toksisitas, uji fitokimia dan identifikasi dengan menggunakan spektrofotometer IR.

\section{Identifikasi}

Identifikasi dilakukan dengan uji fitokimia kandungan senyawa aktif dengan uji reagen dari ekstrak pekat $n$-heksana kulit kayu bitti dilarutkan dengan sedikit masing-masing dengan pelarutnya. Kemudian dilakukan uji alkaloid, uji sterol dan triterpen, uji saponin, dan uji flavonoid.

\section{Fraksinasi dengan KLT, KKCV dan kromatografi gravitasi}

Ekstrak kental yang diperoleh di KLT kemudian diteruskan dengan kromatografi kolom cair vakum (KKCV). Fraksi yang menunjukkan adanya butiran kristal dilanjutkan pada kromatografi gravitasi, sehingga diperoleh fraksi yang lebih sederhana.

\section{Pemurnian}

Pemurnian dilakukan dengan cara kristalisasi dan rekristalisasi dengan pelarut yang cocok, hingga diperoleh kristal murni yang ditandai dengan hasil KLT yang menunjukkan satu noda pada tiga sistem eluen.

\section{Identifikasi ekstrak kayu Bitti dengan menggunakan spektrofotometer Infra Red (IR)}

Isolat hasil pemurnian disiapkan lalu ditumbuk hingga memenuhi ukuran partikel kurang dari $2 \mu \mathrm{m}$, kemudian dimasukkan ke dalam pellet press secara merata. Pellet press dihubungkan ke pompa vakum selama 15 menit diusahakan pellet yang terbentuk mempunyai ketebalan 0,3 $\mathrm{mm}$ (transparan), selanjutnya dibuka pellet secara hati-hati dan dipindahkan ke dalam sel holder menggunakan spatula. Setelah itu diatur alat spektrometer Infra Merah (IR) dengan kecepatan kertas pada posisi 
"normal" dan ekspansi transmisi "100x". Skala kertas diuji melalui pembuatan spektrum dari film polystiren. Apabila skala kertas sudah tepat, maka dengan cara yang sama dibuat sepktrum Infra Merah dari sampel yang sudah disiapkan, kemudian ditentukan gugus-gugus fungsi.

\section{Uji Toksisitas}

1. Menyemai Benur (menetaskan telur Udang)

a. Volume air laut diukur sebanyak $300 \mathrm{~mL}$.

b. Air laut dituang dalam wadah penetasan, kemudian telur Artemia salina diletakkan pada sisi wadah yang tertutup sebagian (wadah dijauhkan dari sinar matahari langsung).

c. Dibiarkan selama $2 \times 24$ jam sampai menetas menjadi benur (Naupli) yang siap digunakan.

\section{Penyiapan sampel}

a. Sampel (ekstrak pekat $n$-heksana, fraksi dan senyawa murni) masing-masing ditimbang $1,0 \mathrm{mg}$ dalam botol vial, dilarutkan dalam $100 \mu$ L DMSO.

b. Larutan sampel diencerkan dengan $150 \mu \mathrm{L}$ aquabides sehingga volume total menjadi 250 $\mu \mathrm{L}$, diambil $200 \mu \mathrm{L}$ diencerkan dengan 600 $\mu \mathrm{L}$ aquabides sehingga volume total menjadi $800 \mu \mathrm{L}$.

c. Pengenceran dalam microplate. Pengukuran dilakukan triplo (tiga kali). Dalam microplate baris A dan B diisi sampel masing-masing $100 \mu \mathrm{L}$

d. Baris B sampai G ditambahkan $100 \mu \mathrm{L}$ aquabides

e. Dari baris B dipipet $100 \mu \mathrm{L}$, dimasukkan ke baris $\mathrm{C}$, dan dari baris $\mathrm{C}$ dipipet $100 \mu \mathrm{L}$ dimasukkan ke D dan seterusnya.

f. Terakhir dari $\mathrm{G}$ dipipet $100 \mu \mathrm{L}$ dan dimasukkan ke $\mathrm{H}$.

Catatan: Kolom H tidak digunakan dalam pengukuran.

\section{Memasukkan Benur Larva}

a. Media udang yag sudah menetas (berisi sekitar $\quad 7-15$ ekor) dipipet $100 \mu \mathrm{L}$, dimasukkan masing-masing ke dalam lubang baris A sampai G pada mikropipet yang telah diisi sampel melalui pengenceran pada $\mathrm{B}$, kemudian diinkubasi selama 24 Jam.

Setelah 24 jam, dihitung jumlah udang yang mati dan hidup pada tiap lubang dalam microplate. Data yang diperoleh dicatat pada lembar pengamatan.

\section{HASIL DAN PEMBAHASAN}

Serbuk kering kulit batang V.cofassus diekstraksi dengan menggunakan metode maserasi pada suhu kamar dengan menggunakan pelarut $\mathrm{n}$-heksana yang mampu mengikat senyawa-senyawa nonpolar.Pada proses ekstraksi ini terjadi pemindahan massa senyawa aktif yang semula berada dalam sel, ditarik oleh pelarut $n$-heksana. Penggunaan metode maserasi dipilih untuk mencegah kerusakan senyawa aktif yang terkandung di dalam kulit batang. Hal ini dikarenakan senyawa aktif dalam suatu ekstrak cenderung tidak stabil pada suhu tinggi, sehingga pemanasan pada suhu tinggi perlu dihindari. Maserasi sampel dengan $n$-heksana dilakukan dalam waktu $3 \times 24$ jam hingga diperoleh ekstrak padat berwarna kuning sebanyak 7,5794gram.

Selanjutnya, dilakukan uji fitokimia pada ekstrak $n$-heksana yang menunjukkan hasil bahwa ekstrak $n$ heksana positif mengandung senyawa metabolit sekunder alkaloid, terpenoid dan steroid. Ekstrak $n$ heksana kemudian di uji KLT untuk mengetahui eluen yang baik digunakan pada kromatografi kolom cair vakum (KKCV). Dari beberapa uji eluen, diperoleh eluen $n$-heksana:etil asetat dengan perbandingan 8:2 yang menunjukkan pemisahan noda yang baik dengan penampakan noda yang jelas. Kromatogram hasil uji KLT dengan eluen tersebut menunjukkan gambaran beberapa komponen senyawa yang terkandung dalam ekstrak $n$-heksana.

Ekstrak $n$-heksana selanjutnya difraksinasi dengan kromatografi kolom cair vakum (KKCV) dengan menggunakan adsorben silika gel G60 F254 sebagai fasa diam dan eluen $n$-heksana:etil asetat (8:2) sebagai fasa gerak untuk memisahkan senyawasenyawa pada ekstrak berdasarkan tingkat polaritasnya. Bagian larut $n$-heksana dielusi dengan berbagai komposisi pelarut berdasarkan gradien polaritas, yang dimulai dari pelarut nonpolar yang selanjutnya tingkat kepolaran dinaikkan secara perlahan-lahan.

Hasil fraksinasi tersebut selanjutnya dianalisis menggunakan KLT dengan tujuan pengelompokkan lebih lanjut terhadap fraksi-fraksi yang diperoleh berdasarkan kesamaan profil kandungan kimia dari bercak KLT yang terbentuk dengan nilai $\mathrm{Rf}$ yang sama.

Fraksi hasil KKCV yang menunjukkan adanya tanda-tanda kristal yakni pada fraksi B dilanjutkan pada kromatografi kolom gravitasi, dengan fase diam silika $\mathrm{GF}_{254} 7734$ dan fase gerak berupa eluen $n$ heksana:etil asetat dengan perbandingan komposisi sama dengan yang digunakan pada KKCV dan diperoleh 53 fraksi. Setelah diuapkan, hasil pengamatan menunjukkan bahwa pada fraksi 10-16 nampak adanya kristal putih berbentuk jarum. Selanjutnya, kristal tersebut dianalisis KLT dan nampak bercak noda hanya satu. Untuk memastikan kemurnian kristal tersebut, dilakukan pengujian KLT tiga sistem eluen. Hasil analisis KLT tiga eluen menunjukkan hasil satu noda dengan Rf masingmasing: eluen kloroform: $n$-heksana $\mathrm{Rf}=0,2$; etil asetat: $n$-heksana $\mathrm{Rf}=0,6$, dan etil asetat-kloroform $\mathrm{Rf}$ $=0,8$. Dengan demikian dapat disimpulkan bahwa senyawa yang diperoleh sudah dapat dikategorikan sebagai senyawa murni. Senyawa murni yang didapatkan yaitu seberat 0,4745 gram. Selanjutnya hasil identifikasi uji warna menunjukkan bahwa senyawa murni positif bereaksi 


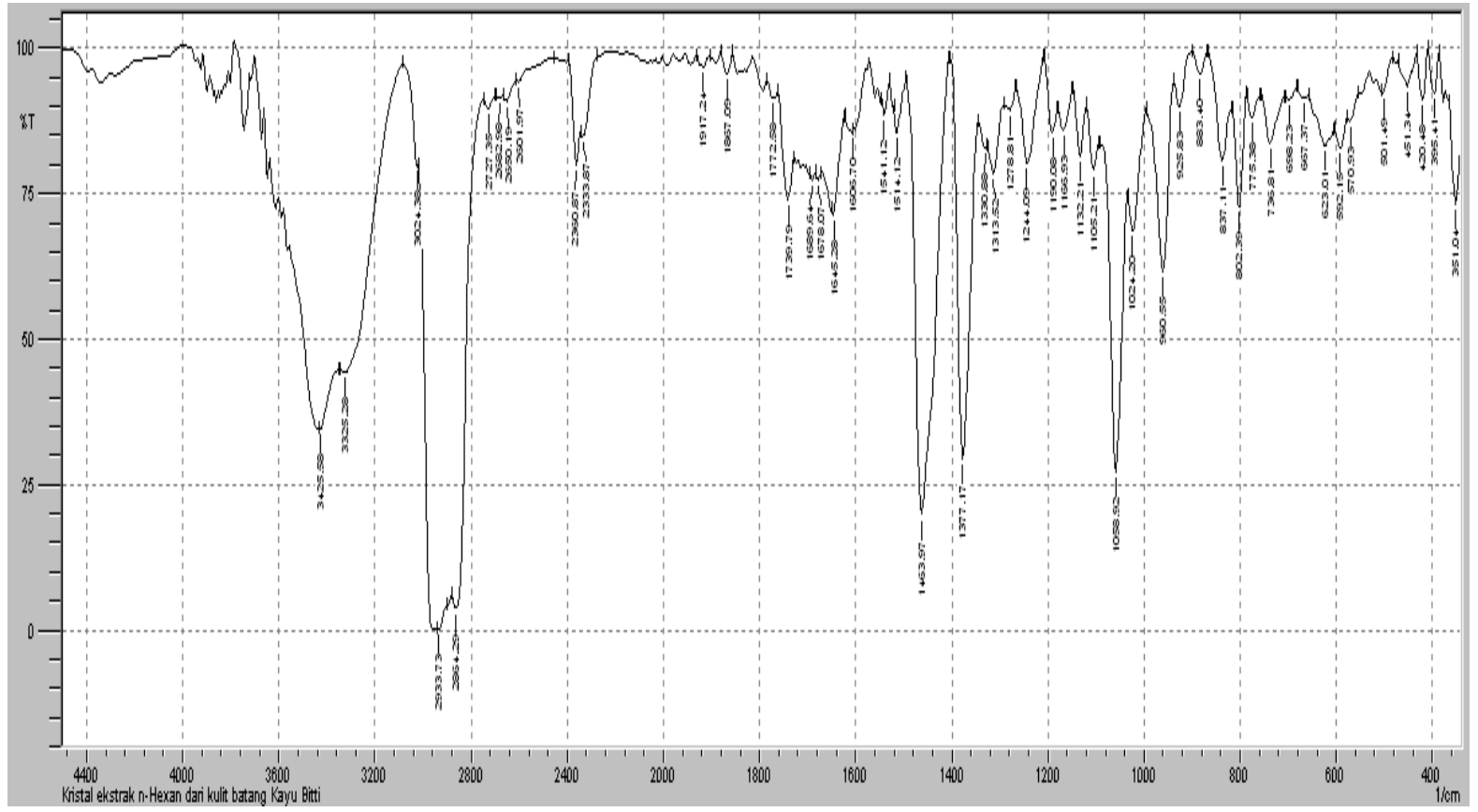

Gambar 1. Spektrum IR senyawa murni.

positif dengan pereaksi Lieberman Burchard yang ditandai adanya warna biru. Hal ini menunjukkan bahwa senyawa tersebut merupakan salah satu senyawa golongan steroid. Pada pereaksi Lieberman Burchard, asam asetat anhidrida dan asam sulfat pekat bereaksi dan menghasilkan warna hijau biru. Reaksi yang terjadi antara steroid dengan asam asetat anhidrat adalah reaksi asetilasi gugus $-\mathrm{OH}$ pada steroid yang akan menghasilkan kompleks asetil steroid.

Hasil karakterisasi spektroskopi Infra Red (IR) yang tertera pada Gambar 1 menghasilkan serapan pada bilangan gelombang $3425,58-3325,28 \mathrm{~cm}^{-1}$ yang menandakan adanya serapan ulur gugus $\mathrm{O}-\mathrm{H}$, adanya pita dengan intensitas kuat pada daerah serapan $3024,38 \mathrm{~cm}^{-1}$ menunjukkan gugus $=\mathrm{C}-\mathrm{H}$, pada serapan 2933,73-2864,29 $\mathrm{cm}^{-1}$ merupakan $\mathrm{C}-\mathrm{H}$, pita tajam dan intensitas kuat pada daerah serapan 1463,97 $\mathrm{cm}^{-1}$ merupakan $\mathrm{CH}_{2}$, sedangkan pada daerah serapan $1377,17 \mathrm{~cm}^{-1}$ adalah $\mathrm{CH}_{3}$ dan pada daerah bilangan gelombang 1058,82 $\mathrm{cm}^{-1}$ menunjukkan uluran $\mathrm{C}-\mathrm{OH}$ siklik. Pita serapan yang menunjukkan adanya gugus $\mathrm{O}-\mathrm{H}$ dan $\mathrm{C}-\mathrm{OH}$ memberikan gambaran bahwa kemungkinan senyawa isolat merupakan suatu senyawa siklik steroid yang mengandung gugus $\mathrm{OH}$.

Brine Shrimp Lethality Test (BSLT) merupakan suatu metode skrining untuk menentukan toksisitas suatu senyawa ekstrak bahan-bahan alami yang bersifat sitotoksik secara akut dengan menggunakan hewan uji larva Artemia salina Leach. Suatu ekstrak dinyatakan mempunyai potensi toksisitas akut jika mempunyai harga $\mathrm{LC}_{50}<1000 \mu \mathrm{g} / \mathrm{mL}$. $\mathrm{LC}_{50}$ (Lethal Concentration 50) merupakan konsentrasi zat yang dapat menyebabkan terjadinya kematian pada $50 \%$ hewan uji yaitu larva Artemia salina Leach. Semakin besar nilai $\mathrm{LC}_{50}$ berarti menunjukkan toksisitasnya semakin kecil dan sebaliknya semakin kecil nilai $\mathrm{LC}_{50}$ semakin besar nilai toksisitasnya

Tabel 1. Tabel Toksisitas Ekstrak $n$-Heksana Kulit Batang Kayu Bitti

\begin{tabular}{lll}
\hline Sampel & \multicolumn{1}{c}{$\begin{array}{c}\text { Nilai } \mathbf{L C}_{\mathbf{5 0}} \\
(\boldsymbol{\mu g} / \mathbf{m L})\end{array}$} & $\begin{array}{c}\text { Tingkat } \\
\text { keaktifan }\end{array}$ \\
\hline $\begin{array}{l}\text { Ekstrak kental n- } \\
\text { heksana }\end{array}$ & 74,079 & Aktif \\
Fraksi & 118,850 & Sedang \\
Kristal murni & 88,201 & Aktif \\
\hline
\end{tabular}

Berdasarkan hasil analisis probit yang menunjukkan harga $\mathrm{LC}_{50}$ ekstrak $n$-heksana sebesar $74,079 \mu \mathrm{g} / \mathrm{mL}$, fraksi sebesar $118,850 \mu \mathrm{g} / \mathrm{mL}$ dan kristal murni sebesar 88,201 $\mu \mathrm{g} / \mathrm{mL}$. Hasil nilai $\mathrm{LC}_{50}$ pada ekstrak, fraksi maupun kristal tersebut menunjukkan bahwa ketiganya bersifat toksik karena memiliki nilai $\mathrm{LC}_{50}<1000 \mu \mathrm{g} / \mathrm{mL}$. Dengan demikian, dapat dikatakan bahwa kulit batang kayu bitti mempunyai potensi untuk dikembangkan sebagai senyawa antikanker. Hasil analisis probit juga menunjukkan bahwa ekstrak $n$-heksana memiliki nilai $\mathrm{LC}_{50}$ yang paling kecil dibandingkan pada fraksi dan kristal. Kemungkinan hal ini dikarenakan pada ekstrak memiliki banyak komponen senyawa teraktifnya, sehingga pada ekstrak $n$-heksana cenderung bersifat lebih toksik dibandingkan pada fraksi maupun kristal. 


\section{KESIMPULAN}

Senyawa bioaktif ekstrak n-heksana kulit batang kayu bitti (Vitex cofassus) diperoleh berupa kristal putih berbentuk jarum seberat 0,4745 gram yang diduga merupakan senyawa golongan steroid.

Nilai $\mathrm{LC}_{50}$ yang diperoleh pada ekstrak $n$-heksana sebesar 74,079 $\mu \mathrm{g} / \mathrm{mL}$, pada fraksi sebesar 118,850 $\mu \mathrm{g} / \mathrm{mL}$ dan kristal murni sebesar $88,201 \mu \mathrm{g} / \mathrm{mL}$, sehingga dapat disimpulkan bahwa kulit batang kayu bitti (Vitex cofassus) bersifat toksik.

\section{DAFTAR PUSTAKA}

Gusmiaty, Restu, M. \& Pongtuluran, I., (2012).

Seleksi Primer Untuk Analisis Keragaman Genetik Jenis Bitti (Vitex coffassus). Jurnal Perennial. 8(1), 25-29.
Hidayat, S. \& Munawaroh, E. (2009). Keanekaragaman Jenis Tumbuhan Liar dan Potensinya di Kawasan Hutan Mangkutana, Kabupaten Luwu Timur, Sulawesi Selatan. Seminar Nasional Etnobotani IV. Cibinong, 18 Mei 2009.

Prasetyawati, A. (2013). Eksplorasi Benih Bitti (Vitex Cofassus) Di Sulawesi Selatan. http://balithutmakassar.org/eksplorasi-benih-bittivitex-cofassus-di-sulawesi-selatan/. (diakses pada tanggal 21 Januari 2014).

Septyaningsih, D. (2010). Isolasi dan Identifikasi Komponen Utama Ekstrak Biji Buah Merah (Pandanus conoideus Lamk.). Skripsi (Surakarta: Fakultas Matematika dan Ilmu Pengetahuan Alam, Universitas Sebelas Maret, Surakarta. 